\title{
Risk factors for erlotinib-induced hepatotoxicity: a retrospective follow-up study
}

\author{
Min Kyoung Kim ${ }^{1,2 \dagger}$, Jeong Yee ${ }^{3 \dagger}$, Yoon Sook Cho ${ }^{2}$, Hong Won Jang ${ }^{2}$, Ji Min Han ${ }^{2,3}$ and Hye Sun Gwak ${ }^{1,3^{*}}$ (D)
}

\begin{abstract}
Background: Erlotinib is a drug used for the treatment of non-small cell lung cancer (NSCLC) and pancreatic cancer. Severe hepatotoxicity was observed in $4 \%$ to $31 \%$ of patients receiving erlotinib treatment prompting delay or termination of treatment. Only a few factors related to hepatotoxicity of erlotinib have been reported. No study has investigated the role of concomitant medications and erlotinib-induced hepatotoxicity. The aim of this study was to investigate the association between erlotinib-induced hepatotoxicity and various factors including concomitant medications in patients with NSCLC and pancreatic cancer.
\end{abstract}

Methods: From January 2014 to June 2017, a retrospective study was conducted in patients with NSCLC and pancreatic cancer, who were treated with erlotinib. Various data were reviewed, including sex, age, body weight, height, body surface area (BSA), underlying disease, Eastern Cooperative Oncology Group (ECOG) Performance Status (PS), smoking history, erlotinib dose, EGFR mutation, and concomitant drugs.

Results: The incidence of grade 2 or higher hepatotoxicity in the study group of patients was $17.2 \%$. Multivariate analysis showed a 2.7-fold increase in hepatotoxicity with the concomitant use of CYP3A4 inducers. In NSCLC patients, cOadministration of $\mathrm{H} 2$-antagonist/PPI increased hepatotoxicity 3.5-fold. Among the demographic factors, liver metastasis and age $\geq 65$ years were significant risk factors in all study patients and NSCLC patients, respectively; the attributable risks for liver metastasis and age were $46.3 \%$ and $71.8 \%$, respectively. Subgroup analysis using pancreatic cancer patients yielded marginally significant results with CYP3A4 inducers and erlotinib-induced hepatotoxicity. Liver metastasis and CYP3A4 inducers also shortened time to hepatotoxicity 2.1 and 2.3-fold, respectively.

Conclusions: Our study showed that concomitant use of CYP3A4 inducers and H2-antagonist/PPI, liver metastasis, and age $\geq 65$ were associated with erlotinib-induced hepatotoxicity. Thus, close monitoring of liver function is recommended, especially in patients using CYP3A4 inducers and anti-acid secreting agents.

Keywords: Erlotinib, Hepatotoxicity, CYP3A4 inducers, H2-antagonist, Proton pump inhibitor

\section{Background}

The reported rates of incidence of lung cancer and pancreatic cancer in Korea are 11.1 and $2.7 \%$, respectively. These cancers are fatal with 5-year survival rates of $25.1 \%$ and $10.1 \%$, respectively [1]. Lung cancer and pancreatic

\footnotetext{
*Correspondence: hsgwak@ewha.ac.kr

${ }^{\dagger}$ Min Kyoung Kim and Jeong Yee contributed equally to this work.

'Graduate School of Converging Clinical \& Public Health, Ewha Womans University, Seoul 03760, Korea

${ }^{3}$ College of Pharmacy \& Division of Life and Pharmaceutical Sciences, Ewha

Womans University, 52 Ewhayeodae-gil Seodaemun-gu, Seoul 03760,

Republic of Korea

Full list of author information is available at the end of the article
}

cancer often overexpress epidermal growth factor receptor (EGFR), which is associated with a worse prognosis [2, 3].

Erlotinib, an EGFR tyrosine kinase inhibitor (TKI), is used for the treatment of non-small cell lung cancer (NSCLC) and pancreatic cancer. Erlotinib has been shown to prolong survival and decrease symptoms compared with placebo in previously treated patients with NSCLC [4]. Studies also showed that erlotinib improved progression-free survival compared with chemotherapy as a first-line treatment in Asian patients with NSCLC carrying activating EGFR mutations [5]. Patients with advanced pancreatic cancer show poor diagnosis, and

(c) The Author(s). 2018 Open Access This article is distributed under the terms of the Creative Commons Attribution 4.0 International License (http://creativecommons.org/licenses/by/4.0/), which permits unrestricted use, distribution, and 
gemcitabine monotherapy fails to improve survival rate. The addition of EGFR TKIs such as erlotinib to gemcitabine demonstrated a significantly higher survival rate in patients diagnosed with pancreatic cancer [3].

Common toxicities associated with erlotinib are mostly mild in severity and manageable, and include skin rash, diarrhea, and nausea [6]. Hepatotoxicity involving elevated liver transaminase level grade 2 or higher according to the Common Terminology Criteria for Advanced Events (CTCAE), Version 4.0 has been observed in 31\% of pancreatic cancer patients and 4\% NSCLC patients receiving erlotinib treatment $[3,6]$. Severe hepatotoxicity is not frequent; however, patients who experience hepatotoxicity while receiving erlotinib often need to postpone or terminate treatment.

The cause of erlotinib-induced hepatotoxicity is unknown. Erlotinib is metabolized in the liver mainly by cytochrome P450 (CYP)3A4 and minimally by CYP1A1 and CYP1A2. O-desmethylated erlotinib, the major metabolite, is found in human plasma [7]. Cytolytic hepatitis is caused by several factors including toxic metabolic intermediates, autoimmune injury, and direct EGFR TKI inhibition [8]. However, studies investigating the toxicity mechanisms mainly involved gefitinib-induced hepatotoxicity. Only a few cases of erlotinib-induced hepatotoxicity have been reported. The role of concomitant medications and erlotinib-induced hepatotoxicity has not been studied. Therefore, the aim of this current study was to investigate the association between erlotinib-induced hepatotoxicity and various factors including concomitant medications in pancreatic cancer and NSCLC patients.

\section{Methods}

\section{Patients}

From January 2014 to June 2017, a retrospective study was performed with patients who were older than 18 years and treated with erlotinib at Seoul National University Hospital, Korea. The exclusion criteria were: patients who were not diagnosed with NSCLC or pancreatic cancer, had underlying liver diseases (fatty liver, alcoholic liver cirrhosis, and hepatitis), an elevated aspartate aminotransferase (AST) or alanine aminotransferase (ALT) level on day one of erlotinib administration, and lack of liver function test results. This study was approved by the Seoul National University Hospital Institutional Review Board (IRB \# H-1710-087-894).

The following data were collected: sex, age, body weight, height, body surface area (BSA), underlying disease, Eastern Cooperative Oncology Group (ECOG) Performance Status (PS), smoking history, erlotinib dosage, EGFR mutations, and concomitant drug usage. Concomitant drugs included CYP3A4 inhibitors, CYP3A4 inducers, CYP2D6 inhibitors, H2-antagonists, and proton pump inhibitors (PPI). The CYP3A4 inhibitors included amiodarone, aprepitant, atazanavir, cimetidine, ciprofloxacin, clarithromycin, danazol, diltiazem, fluconazole, fluoxetine, fluvoxamine, imatinib, itraconazole, lapatinib, nicardipine, nifedipine, ritonavir, verapamil, and voriconazole. The CYP3A4 inducers included carbamazepine, dexamethasone, efavirenz, ethosuximide, etravirine, naficillin, oxcarbazepine, phenobarbital, phenytoin, primidone, rifabutin, and rifampicin (rifampin). The H2-antagonists included cimetidine, famotidine, nizatidine, and ranitidine. The PPIs included (es)omeprazole, (dex)lansoprazole, pantoprazole, and rabeprazole.

\section{Erlotinib administration and laboratory assessment}

Patients with NSCLC were treated with an erlotinib dose of $150 \mathrm{mg}$ and those diagnosed with pancreatic cancer were adminstered $100 \mathrm{mg}$ of the same drug. Gemcitabine was prescribed for patients with pancreatic cancer at a dose of $1000 \mathrm{mg} / \mathrm{m}^{2}$. Liver function was tested at 23 weeks after erlotinib therapy initially, and every 2 to 3 months thereafter. Serum ALT and AST levels were evaluated. The hepatotoxicity grade was determined using the Common Terminology Criteria for Adverse Events (CTCAE), Version 4.0. The CTCAE defines grades I, II, III, and IV toxicity levels of AST and ALT as 1.0-3.0 times, 3.0-5.0 times, 5.0-20.0 times, and more than 20 times the upper limit of normal, respectively. In this study, hepatotoxicity was defined as grade II or higher.

\section{Statistical analysis}

The chi-squared test or Fisher's exact test were used to compare the categorical variables between patients with and without hepatotoxicity. Multivariable logistic regression analysis was used to identify independent risk factors for hepatotoxicity. Factors with $p$-values $<0.1$ from univariate analysis along with strong confounders such as sex were included in multivariate analysis. Odds ratio (OR) and adjusted odds ratio (AOR) were calculated from univariate and multivariate analyses, respectively. Attributable risk was calculated by $1-1 / \mathrm{OR}$. The time to hepatotoxicity and recovery was analyzed using the Kaplan-Meier survival curves and the log-rank test. Cox's proportional-hazards model was used for multivariate analysis. Hazard ratio (HR) and adjusted hazard ratio (AHR) were calculated from univariate and multivariate analyses, respectively. $P$-values less than 0.05 were considered statistically significant. All statistical analyses were carried out using the Statistical Package for Social Sciences (SPSS) version 17.0 for Windows (Inc., Chicago, IL, USA).

\section{Results}

A total of 448 patients were eligible for participation in the study from January 2014 to June 2017. The following 
Table 1 Hepatotoxicity related to erlotinib administration

\begin{tabular}{|c|c|c|c|c|c|c|}
\hline \multirow[t]{3}{*}{ Characteristics } & \multicolumn{2}{|l|}{ All patients } & \multicolumn{2}{|l|}{ Lung cancer } & \multicolumn{2}{|l|}{ Pancreatic cancer } \\
\hline & \multicolumn{2}{|c|}{ Hepatotoxicity No (\%) } & \multicolumn{2}{|c|}{ Hepatotoxicity No (\%) } & \multicolumn{2}{|c|}{ Hepatotoxicity No (\%) } \\
\hline & Presence $(n=62)$ & Absence $(n=298)$ & Presence $(n=16)$ & Absence $(n=139)$ & Presence $(n=46)$ & Absence $(n=159)$ \\
\hline \multicolumn{7}{|l|}{ Age (years) } \\
\hline$<65$ & $28(45.2)$ & $155(52.0)$ & $6(37.5)$ & $85(61.2)$ & $22(47.8)$ & $70(44.0)$ \\
\hline$\geq 65$ & $34(54.8)$ & $143(48.0)$ & $10(62.5)$ & $54(38.8)$ & $24(52.2)$ & $89(56.0)$ \\
\hline \multicolumn{7}{|l|}{ Sex } \\
\hline Male & $35(56.5)$ & $182(61.1)$ & $8(50.0)$ & $87(62.6)$ & $27(58.7)$ & $95(59.7)$ \\
\hline Female & $27(43.5)$ & $116(38.9)$ & $8(50.0)$ & $52(37.4)$ & $19(41.3)$ & $64(40.3)$ \\
\hline \multicolumn{7}{|l|}{ BW (kg) } \\
\hline$<60$ & $38(61.3)$ & $162(54.4)$ & $6(37.5)$ & $70(50.4)$ & $32(69.6)$ & $92(57.9)$ \\
\hline$\geq 60$ & $24(38.7)$ & $136(45.6)$ & $10(62.5)$ & 69 (49.6) & $14(30.4)$ & $67(42.1)$ \\
\hline \multicolumn{7}{|l|}{ Height $(\mathrm{cm})^{a}$} \\
\hline$<160$ & $27(43.5)$ & $115(38.7)$ & $8(50.0)$ & $45(32.4)$ & $19(41.3)$ & $70(44.3)$ \\
\hline$\geq 160$ & $35(56.5)$ & $182(61.3)$ & $8(50.0)$ & $94(67.6)$ & $27(58.7)$ & $88(55.7)$ \\
\hline \multicolumn{7}{|l|}{$B S A^{b}$} \\
\hline$<1.6$ & $32(51.6)$ & $130(43.8)$ & $5(31.3)$ & $54(38.8)$ & $27(58.7)$ & $76(48.1)$ \\
\hline$\geq 1.6$ & $30(48.4)$ & $167(56.2)$ & $11(68.6)$ & $85(61.2)$ & $19(41.3)$ & $82(51.9)$ \\
\hline \multicolumn{7}{|l|}{ Stage ${ }^{c}$} \\
\hline $1-3$ & $6(14.3)$ & $27(14.4)$ & $0(0.0)$ & $5(5.0)$ & $6(20.7)$ & $22(25.0)$ \\
\hline 4 & $36(85.7)$ & 161 (85.6) & $13(100.0)$ & $95(95.0)$ & $23(79.3)$ & $66(75.0)$ \\
\hline \multicolumn{7}{|l|}{ CV } \\
\hline Yes & $15(24.2)$ & $83(27.9)$ & $1(6.3)$ & $25(18.0)$ & $14(30.4)$ & $58(36.5)$ \\
\hline No & $47(75.8)$ & $215(72.1)$ & 15 (93.8) & $114(82.0)$ & 32 (69.6) & $101(63.5)$ \\
\hline \multicolumn{7}{|l|}{ DM } \\
\hline Yes & $18(29.0)$ & $66(22.1)$ & $1(6.3)$ & $17(12.2)$ & $17(37.0)$ & 49 (30.8) \\
\hline No & $44(71.0)$ & 232 (77.9) & 15 (93.8) & $122(87.8)$ & $29(63.0)$ & $110(69.2)$ \\
\hline \multicolumn{7}{|c|}{ EGFR mutations ${ }^{d}$} \\
\hline Yes & $9(81.8)$ & $76(69.1)$ & $9(81.8)$ & $76(69.1)$ & NA & NA \\
\hline No & $2(18.2)$ & $34(30.9)$ & $2(18.2)$ & 34 (30.9) & NA & NA \\
\hline \multicolumn{7}{|l|}{ Liver metastasis } \\
\hline Yes & 19 (30.6) & $61(20.5)$ & $2(12.5)$ & $11(7.9)$ & $17(37.0)$ & $50(31.4)$ \\
\hline No & $43(69.4)$ & $237(79.5)$ & $14(87.5)$ & $128(92.1)$ & $29(63.0)$ & 109 (68.6) \\
\hline \multicolumn{7}{|c|}{ CYP3A4 Inhibitor } \\
\hline Yes & $3(4.8)$ & $15(5.0)$ & $2(12.5)$ & $10(7.2)$ & $1(2.2)$ & $5(3.1)$ \\
\hline No & $59(95.2)$ & $283(95.0)$ & $14(87.5)$ & $129(92.8)$ & 45 (97.8) & $154(96.9)$ \\
\hline \multicolumn{7}{|l|}{ CYP3A4 Inducer } \\
\hline Yes & $7(11.3)$ & $15(5.0)$ & $3(18.8)$ & $11(7.9)$ & $4(8.7)$ & $4(2.5)$ \\
\hline No & 55 (88.7) & $283(95.0)$ & $13(81.3)$ & $128(92.1)$ & $42(91.3)$ & $155(97.5)$ \\
\hline \multicolumn{7}{|c|}{ H2 blocker or PPI } \\
\hline Yes & $16(25.8)$ & $56(18.8)$ & $7(43.8)$ & $28(20.1)$ & $9(19.6)$ & $28(17.6)$ \\
\hline No & $46(74.2)$ & $242(81.2)$ & $9(56.3)$ & $111(79.9)$ & $37(80.4)$ & $131(82.4)$ \\
\hline \multicolumn{7}{|l|}{ PPI } \\
\hline Yes & $7(11.3)$ & $23(7.7)$ & $4(25.0)$ & $12(8.6)$ & $3(6.5)$ & $11(6.9)$ \\
\hline No & 55 (88.7) & 275 (92.3) & $12(75.0)$ & $127(91.4)$ & $43(93.5)$ & $148(93.1)$ \\
\hline
\end{tabular}


Table 1 Hepatotoxicity related to erlotinib administration (Continued)

\begin{tabular}{|c|c|c|c|c|c|c|}
\hline \multirow[t]{3}{*}{ Characteristics } & \multicolumn{2}{|l|}{ All patients } & \multicolumn{2}{|l|}{ Lung cancer } & \multicolumn{2}{|l|}{ Pancreatic cancer } \\
\hline & \multicolumn{2}{|c|}{ Hepatotoxicity No (\%) } & \multicolumn{2}{|c|}{ Hepatotoxicity No (\%) } & \multicolumn{2}{|c|}{ Hepatotoxicity No (\%) } \\
\hline & Presence $(n=62)$ & Absence $(n=298)$ & Presence $(n=16)$ & Absence $(n=139)$ & Presence $(n=46)$ & Absence $(n=159)$ \\
\hline \multicolumn{7}{|l|}{ H2 blocker } \\
\hline Yes & $9(14.5)$ & $41(13.8)$ & $3(18.8)$ & $22(15.8)$ & $6(13.0)$ & 19 (11.9) \\
\hline No & $53(85.5)$ & $257(86.2)$ & $13(81.3)$ & $117(84.2)$ & $40(87.0)$ & $140(88.1)$ \\
\hline
\end{tabular}

BW body weight, BSA body surface area, ECOG PS Eastern Cooperative Oncology Group performance scale, CV Cardiovascular diseases, DM Diabetes Mellitus, EGFR epidermal growth factor receptor, $P P I$ proton pump inhibitor, NA not available

${ }^{a}$ There was 1 missing data for height

${ }^{\mathrm{b}}$ There was 1 missing data for BSA

'There were 130 missing data for stage

${ }^{\mathrm{d}}$ There were 34 missing data for EGFR mutation in lung cancer patients

patients were excluded: those who were not diagnosed with NSCLC or pancreatic cancer $(n=8)$, had underlying liver diseases $(n=14)$, had an elevated AST or ALT value on day one of erlotinib administration $(n=30)$, and those without liver function test results $(n=36)$. Accordingly, data from 360 patients were used for the analysis including 155 patients with lung cancer and 205 with pancreatic cancer.

As shown in Table 1, patients' mean age was 64 years (range 28-86); 177 patients (49.2\%) were $\geq 65$ years of age. About $40 \%$ of the study patients were women. Drugs concurrently administered with erlotinib included CYP3A4 inhibitors $(n=18), \quad$ CYP3A4 inducers $(n=22)$, H2-antagonists $(n=50)$, PPI $(n=30)$, and any of the two anti-acid secreting agents $\mathrm{H} 2$-antagonist or PPI (H2-antagonist/PPI, $n=72$ ). The incidence of hepatotoxicity was $17.2 \%$; the frequency of hepatotoxicity in patients with lung and pancreatic cancer was $10.3 \%$ and $22.4 \%$, respectively.

Multivariate analysis showed that liver metastasis and CYP3A4 inducers increased hepatotoxicity after controlling for variables with $P$ value less than 0.1 from univariate analysis; the attributable risk of liver metastasis and CYP3A4 inducers was $46.3 \%$ and $62.4 \%$, respectively (Table 2).

The proportion of patients in each CTCAE hepatotoxicity grade was shown in Fig. 1. Twenty-two patients

Table 2 Univariate and multivariate regression analysis to identify predictors for hepatotoxicity related to erlotinib administration

\begin{tabular}{llll}
\hline Characteristics & $\begin{array}{l}\text { Unadjusted OR } \\
(95 \% \mathrm{Cl})\end{array}$ & $\begin{array}{l}\text { Adjusted OR } \\
(95 \% \mathrm{Cl})\end{array}$ & $\begin{array}{l}\text { Attributable } \\
\text { risk }\end{array}$ \\
\hline Male & $0.826(0.475-1.437)$ & $0.987(0.516-1.886)$ & \\
Age $\geq 65$ & $1.316(0.760-2.280)$ & $1.257(0.718-2.203)$ & \\
BSA $\geq 1.6^{\text {a }}$ & $0.730(0.422-1.263)$ & $0.728(0.383-1.385)$ & \\
Liver metastasis & $1.717(0.934-3.156)$ & $1.862(1.001-3.465)^{*}$ & 46.3 \\
CYP3A4 Inducer & $2.401(0.936-6.162)$ & $2.660(1.013-6.982)^{*}$ & 62.4
\end{tabular}

For multivariate analysis, factors with $p<0.1$ in the univariate analysis were included in addition to sex, age and BSA

$B S A$ body surface area

${ }^{\text {a }}$ There was 1 missing data for BSA

${ }^{*} P<0.05$
(6\%) and 6 patients (2\%) experienced grade III and grade IV hepatotoxicity, respectively. Diabetes mellitus (DM), pancreatic cancer, and liver metastasis were most frequently observed in patients with grade III and IV hepatotoxicity; while DM was a significant factor (AOR 2.3, 95\% CI 1.0-5.1), the latter two were of marginal significance. Among 6 patients with grade IV hepatotoxicity, two-third of patients had pancreatic cancer, and the remaining 2 lung cancer patients had EGFR mutation, although there was no statistically significant factor.

For the analysis of lung cancer subgroup (Table 3), two models were constructed since PPIs were included in $\mathrm{H} 2$-antagonist/PPI. Model I included PPI, in addition to age, sex, and BSA and Model II included H2-antagonist/ PPI instead of PPI in Model I. Age $\geq 65$ (AOR 3.2 3.5) and $\mathrm{H} 2$-antagonist/PPI (AOR 3.5) were significant risk factors for hepatotoxicity after adjusting for confounders.

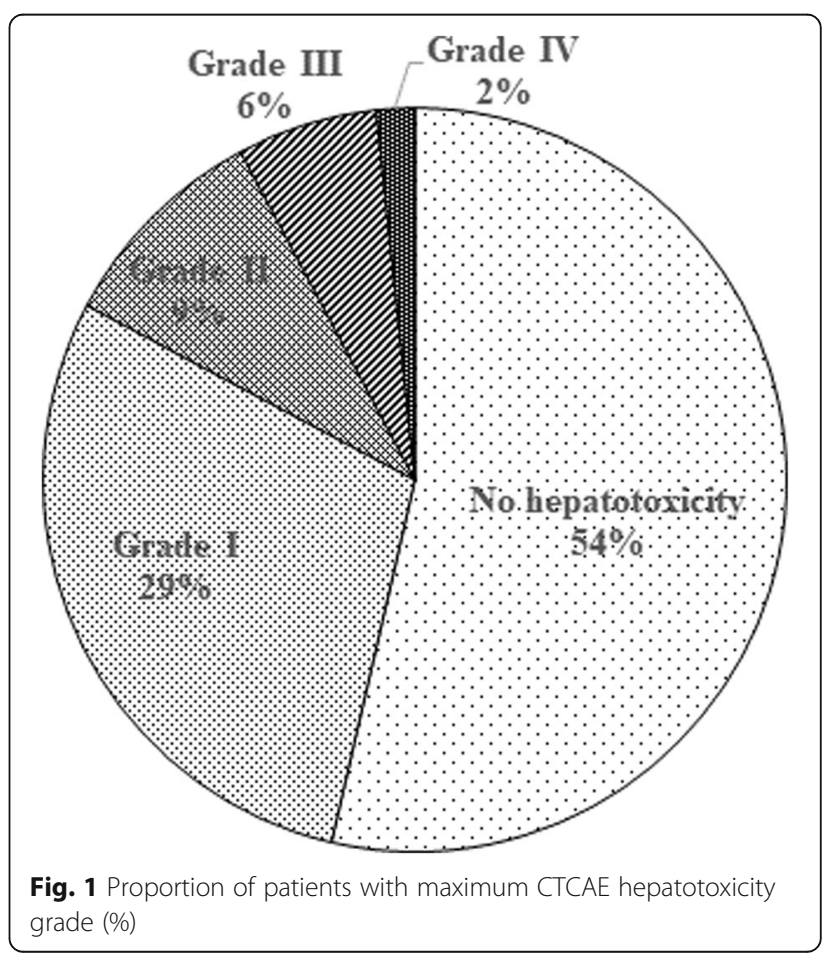


Table 3 Univariate and multivariate regression analysis to identify predictors for hepatotoxicity related to erlotinib administration in lung cancer patients

\begin{tabular}{|c|c|c|c|c|c|}
\hline \multirow[t]{2}{*}{ Characteristics } & \multirow{2}{*}{$\begin{array}{l}\text { Unadjusted OR } \\
(95 \% \mathrm{Cl})\end{array}$} & \multicolumn{2}{|l|}{ Model I } & \multicolumn{2}{|l|}{ Model II } \\
\hline & & Adjusted OR (95\% Cl) & Attributable risk & Adjusted OR (95\% Cl) & Attributable risk \\
\hline Male & $0.598(0.212-1.688)$ & $0.251(0.060-1.048)$ & & $0.266(0.065-1.084)$ & \\
\hline Age $\geq 65$ & $2.623(0.902-7.633)$ & $3.198(1.023-9.997)^{*}$ & 68.7 & $3.540(1.123-11.164)^{*}$ & 71.8 \\
\hline$B S A \geq 1.6$ & $1.398(0.460-4.244)$ & $3.545(0.787-15.972)$ & & $3.188(0.723-14.053)$ & \\
\hline PPI & $3.528(0.984-12.651)$ & 3.529 (0.916-13.595) & & & \\
\hline H2 blocker or PPI & $3.083(1.056-9.000)^{*}$ & & & $3.454(1.114-10.713)^{*}$ & 71.0 \\
\hline
\end{tabular}

For model I construction, sex, age, BSA and PPI were included for analysis. For model II construction, sex, age, BSA and H2 blocker or PPI were included for analysis

$B S A$ body surface area, $P P I$ proton pump inhibitor

$* P<0.05$

In the subgroup analysis using pancreatic cancer patients, only CYP3A4 inducers showed marginal significance in the multivariate analysis $(p=0.055)$ (Table 4).

Significant factors for time to hepatotoxicity were liver metastasis (AHR 2.1, 95\% CI 1.2-3.6) and CYP3A4 inducers (AHR 2.3, 95\% CI 1.0-5.2) based on multivariate analysis (Table 5). As shown in Fig. 2, the mean time to hepatotoxicity in patients with and without CYP3A4 inducers was 598.9 and 1020.8 days $(p=0.075)$.

Meanwhile, the median time to recovery from hepatotoxicity incidence was 71.0 days (range: $42.4 \sim 99.6$ days). There was no significant factor on time to recovery in this study population.

\section{Discussion}

We found that the concomitant use of CYP3A4 inducers increased hepatotoxicity 2.7-fold. In NSCLC patients, co-administration of H2-antagonist/PPI increased hepatotoxicity 3.5-fold. Among the demographic factors, liver metastasis and age $\geq 65$ years were significant risk factors in all study patients and NSCLC patients, respectively; the attributable risk of liver metastasis and age was $46.3 \%$ and $71.8 \%$, respectively. Subgroup analysis using pancreatic cancer patients yielded marginally significant results with CYP3A4 inducers and erlotinib-induced hepatotoxicity.

Table 4 Univariate and multivariate regression analysis to identify predictors for hepatotoxicity related to erlotinib administration in pancreatic cancer patients

\begin{tabular}{lll}
\hline Characteristics & $\begin{array}{l}\text { Unadjusted OR } \\
(95 \% \mathrm{Cl})\end{array}$ & $\begin{array}{l}\text { Adjusted OR } \\
(95 \% \mathrm{Cl})\end{array}$ \\
\hline Male & $0.957(0.491-1.865)$ & $1.279(0.598-2.737)$ \\
Age $\geq 65$ & $0.858(0.444-1.656)$ & $0.731(0.369-1.448)$ \\
BSA $\geq 1.6^{\text {a }}$ & $0.652(0.336-1.268)$ & $0.549(0.255-1.180)$ \\
CYP3A4 Inducer & $3.690(0.886-15.679)$ & $4.114(0.969-17.465)$
\end{tabular}

For multivariate analysis, factors with $p<0.1$ in the univariate analysis were included in addition to sex, age and BSA

$B S A$ body surface area

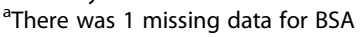

Liver metastasis and CYP3A4 inducers also shortened time to hepatotoxicity 2.1 and 2.3-fold, respectively.

Erlotinib is extensively metabolized by CYP3A4 [7]. Concomitant use of CYP3A4 inducer reduces its exposure [9]; however, it increases the formation of metabolites, which may induce clinically adverse drug reactions. The mechanism of EGFR TKI-induced hepatotoxicity is not well-established. However, various EGFR TKIs have been shown to induce the formation of reactive metabolites leading to hepatotoxicity [10-12]. Erlotinib, one of the EGFR TKIs, is also oxidized to reactive epoxide and quinone-imine by cytochrome P450 [10]. In our previous study [13], CYP3A4 inducer was one of the significant factors underlying hepatotoxicity in NSCLC patients receiving gefitinib treatment in univariate analysis, although statistical significance was not observed in multivariate analysis. Similarly, combination of lapatinib and dexamethasone, one of the CYP3A4 inducers, showed 4.6-fold and 3.5-fold increased risk of hepatotoxicity and clinically important changes in ALT, respectively [14].

Pancreatic cancer patients showed higher hepatotoxicity incidence than NSCLC patients, consistent with results from another study [3, 6]. Concomitant use of gemcitabine chemotherapy was cited as one of the reasons for the higher incidence of hepatotoxicity in

Table 5 Univariate and multivariate analyses to identify predictors for time to hepatotoxicity related to erlotinib administration

\begin{tabular}{lll}
\hline Characteristics & Unadjusted HR $(95 \% \mathrm{Cl})$ & Adjusted HR $(95 \% \mathrm{Cl})$ \\
\hline Male & $0.876(0.530-1.448)$ & $1.045(0.579-1.886)$ \\
Age $\geq 65$ & $1.314(0.797-2.169)$ & $1.265(0.764-2.095)$ \\
BSA $\geq 1.6^{\text {a }}$ & $0.795(0.483-1.309)$ & $0.771(0.431-1.377)$ \\
Liver metastasis & $1.897(1.100-3.275)^{* *}$ & $2.052(1.179-3.572)^{*}$ \\
CYP3A4 inducer & $2.017(0.918-4.433)$ & $2.318(1.029-5.221)^{*}$ \\
\hline
\end{tabular}

For multivariate analysis, factors with $p<0.1$ in the univariate analysis were included in addition to sex, age and BSA

$B S A$ body surface are

There was 1 missing data for BSA

${ }^{*} P<0.05,{ }^{* *} P<0.01$ 


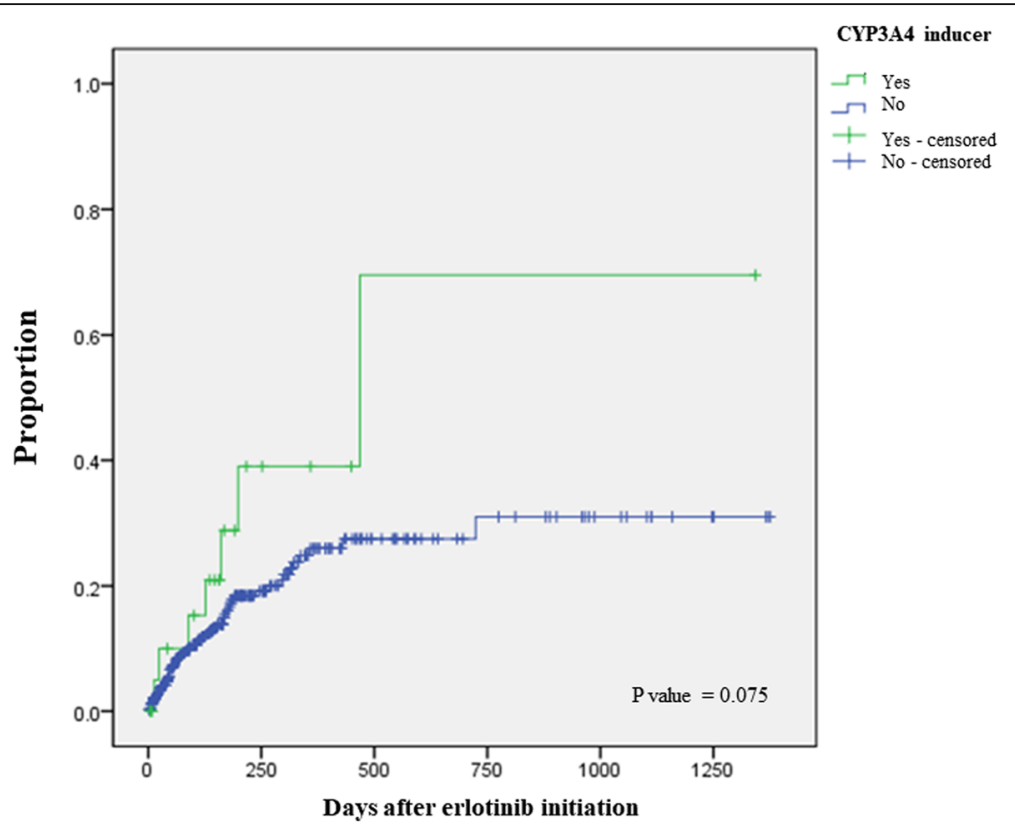

Fig. 2 Kaplan-Meier curve of time to erlotinib-induced hepatotoxicity comparing patients with and without concomitant use of CYP3A4 inducers

patients with pancreatic cancer. Gemcitabine also induces hepatotoxicity, although rarely [15].

Age 65 years and older was a risk factor for hepatotoxicity in the subgroup analysis of NSCLC patients, which contrasted with our previous gefitinib study correlating younger age with higher hepatotoxicity [13]. Considering that older individuals are usually more vulnerable to drug-induced diseases, the erlotinib result was not a surprise. In addition, other study supported this result; significantly higher rates of adverse drug reactions such as rash, tiredness, stomatitis, and dehydration were found in NSCLC patients aged 70 and above [16].

Erlotinib is known to be a substrate for adenosine triphosphate-binding cassette transporters (ABCB1, $\mathrm{ABCG} 2$, and $\mathrm{ABCC} 10)$ [17]. $\mathrm{ABCG} 2$ and $\mathrm{ABCB} 1$ are expressed not only in tumor tissues but also in normal tissues including the liver [18]. PPIs and $\mathrm{H} 2$-antagonists are $A B C G 2$ and $A B C B 1$ inhibitors, which increase the concentration of ABCG2 and ABCB1 substrates such as erlotinib in the liver, resulting in hepatotoxicity. In our previous study on gefitinib, co-administration of PPIs and H2-antagonists showed significantly increased hepatotoxicity in NSCLC patients [13]. Another study evaluated the genetic polymorphism of $\mathrm{ABC}$ transporters on erlotinib-related adverse effects [19]. While the results did not reinforce the association between hepatotoxicity and genetic polymorphisms, they suggested that ABCG2 34G > A was a useful predictor of skin rash of grade 2 or higher level. Further, patients carrying ABCG2 -15,622 T/T polymorphism and ABCG2 (1143C/T, $-15622 \mathrm{C} / \mathrm{T})$ haplotype developed significantly higher frequency of grade $2 / 3$ diarrhea [20]. Based on the genetic results, ABCG2 represents a candidate marker of erlotinib-induced adverse reactions including hepatotoxicity.

The study limitations relate to the retrospective single-center design. In addition, EGFR mutation results were available only in NSCLC patients. Although patients with EGFR mutations manifested around 2.0-fold higher hepatotoxicity compared with those without mutation, no statistical significance was found $(p=0.379)$, possibly due to the small sample size $(n=155)$. However, to our knowledge, this is the first report to investigate the effect of concomitant drug use on erlotinib-induced hepatotoxicity. Also, this study is meaningful due to the large number of patients.

\section{Conclusions}

In conclusion, our study showed that concomitant use of CYP3A4 inducers and H2-antagonist/PPI, liver metastasis, and age $\geq 65$ were associated with erlotinib-induced hepatotoxicity. Thus, close monitoring of liver function is recommended, especially in patients using CYP3A4 inducers and anti-acid secreting agents.

\section{Abbreviations}

AHR: Adjusted hazard ratio; ALT: Alanine aminotransferase; AOR: Adjusted odds ratio; AST: Aspartate aminotransferase; BSA: Body surface area;

CTCAE: Common Terminology Criteria for Advanced Events;

CYP: Cytochrome P450; ECOG: Eastern Cooperative Oncology Group;

EGFR: Epidermal growth factor receptor; HR: Hazard ratio; NSCLC: Non-small

cell lung cancer; OR: Odds ratio; PPI: Proton pump inhibitors;

PS: Performance Status; TKI: Tyrosine kinase inhibitor 


\section{Availability of data and materials}

The datasets used during current study are available from corresponding author on reasonable request.

\section{Authors' contributions}

MKK, JY, YSC, HWJ, and HSG made substantial contributions to conception and design of study. MKK, JY, JMH and HSG made acquisition and analysis of data. MKK, JY and HSG made an interpretation of data. MKK, JY, HWJ, and JMH have been involved in drafting the manuscript. YSC and HSG have been involved in revising the manuscript. All authors approved the manuscript to be published.

\section{Ethics approval and consent to participate}

This study was approved by the Seoul National University Hospital Institutional Review Board (IRB \# H-1710-087-894). The informed consent of participants was waived by the Seoul National University Hospital Institutional Review Board.

\section{Consent for publication}

Not applicable.

\section{Competing interests}

The authors declare that they have no competing interests.

\section{Publisher's Note}

Springer Nature remains neutral with regard to jurisdictional claims in published maps and institutional affiliations.

\section{Author details}

'Graduate School of Converging Clinical \& Public Health, Ewha Womans University, Seoul 03760, Korea. ${ }^{2}$ Department of Pharmacy, Seoul National University Hospital, Seoul 03080, Korea. ${ }^{3}$ College of Pharmacy \& Division of Life and Pharmaceutical Sciences, Ewha Womans University, 52

Ewhayeodae-gil Seodaemun-gu, Seoul 03760, Republic of Korea.

Received: 21 January 2018 Accepted: 3 October 2018

Published online: 16 October 2018

\section{References}

1. Korea Central Cancer Registry, National Cancer Center. Annual report of cancer statistics in Korea in 2014. Sejongsi: Ministry of Health and Welfare; 2016.

2. Hirsch FR, Varella-Garcia M, Bunn PA Jr, et al. Epidermal growth factor receptor in non-small-cell lung carcinomas: correlation between gene copy number and protein expression and impact on prognosis. J Clin Oncol. 2003;21:3798-807.

3. Moore MJ, Goldstein D, Hamm J, et al. Erlotinib plus gemcitabine compared with gemcitabine alone in patients with advanced pancreatic cancer: a phase III trial of the National Cancer Institute of Canada clinical trials group. J Clin Oncol. 2007:25:1960-6.

4. Shepherd FA, Pereira JR, Ciuleanu T, et al. Erlotinib in previously treated non-small-cell lung cancer. N Engl J Med. 2005;353:123-32.

5. Zhou C, Wu Y-L, Chen G, et al. Erlotinib versus chemotherapy as first-line treatment for patients with advanced EGFR mutation-positive non-small-cell lung cancer (OPTIMAL, CTONG-0802): a multicentre, open-label, randomised, phase 3 study. Lancet Oncol. 2011;12:735-42.

6. Canada R. Prescribing information Tarceva (erlotinib). 2013. http://www. accessdata.fda.gov/drugsatfda_docs/label/2013/021743s018lbl.pdf. Accessed 22 Feb 2016.

7. Li J, Zhao M, He P, et al. Differential metabolism of gefitinib and erlotinib by human cytochrome P450 enzymes. Clin Cancer Res. 2007:13:3731-7.

8. Chen J, Gu R, Wan Q, et al. Gefitinib-induced hepatotoxicity in patients treated for non-small cell lung cancer. Onkologie. 2012;35:509-13.

9. Hamilton $\mathrm{M}$, Wolf $\mathrm{JL}$, Drolet DW, et al. The effect of rifampicin, a prototypical CYP3A4 inducer, on erlotinib pharmacokinetics in healthy subjects. Cancer Chemother Pharmacol. 2014;73:613-21.

10. Li X, Kamenecka TM, Cameron MD. Cytochrome P450-mediated bioactivation of the epidermal growth factor receptor inhibitor erlotinib to a reactive electrophile. Drug Metab Dispos. 2010;38:1238-45.

11. Teng WC, Oh JW, New LS, et al. Mechanism-based inactivation of cytochrome P450 3A4 by lapatinib. Mol Pharmacol. 2010;78:693-703.
12. Li X, Kamenecka TM, Cameron MD. Bioactivation of the epidermal growth factor receptor inhibitor gefitinib: implications for pulmonary and hepatic toxicities. Chem Res Toxicol. 2009;22:1736-42.

13. Cho S, Yee J, Kim JY, et al. Effects of concomitant medication use on Gefitinib-induced hepatotoxicity. J Clin Pharmacol. 2018;58:263-8.

14. Teo YL, Saetaew M, Chanthawong S, et al. Effect of CYP3A4 inducer dexamethasone on hepatotoxicity of lapatinib: clinical and in vitro evidence. Breast Cancer Res Treat. 2012;133:703-11.

15. King PD, Perry MC. Hepatotoxicity of chemotherapy. Oncologist. 2001;6:162-76.

16. Wheatley-Price P, Ding K, Seymour L, et al. Erlotinib for advanced non-smallcell lung cancer in the elderly: an analysis of the national cancer institute of Canada clinical trials group study BR.21. J Clin Oncol. 2008;26:2350-7.

17. Beretta $G L$, Cassinelli G, Pennati M, et al. Overcoming ABC transportermediated multidrug resistance: the dual role of tyrosine kinase inhibitors as multitargeting agents. Eur J Med Chem. 2017:142:271-89.

18. Sharom FJ. ABC multidrug transporters: structure, function and role in chemoresistance. Pharmacogenomics. 2008;9:105-27.

19. Tamura M, Kondo M, Horio M, et al. Genetic polymorphisms of the adenosine triphosphate-binding cassette transporters $(A B C G 2, A B C B 1)$ and erlotinib toxicity. Nagoya J Med Sci. 2012;74:133-40.

20. Lemos C, Giovannetti E, Zucali PA, et al. Impact of ABCG2 polymorphisms on the clinical outcome and toxicity of erlotinib in non-small-cell lung cancer patients. Pharmacogenomics. 2011;12:159-70.

\section{Ready to submit your research? Choose BMC and benefit from:}

- fast, convenient online submission

- thorough peer review by experienced researchers in your field

- rapid publication on acceptance

- support for research data, including large and complex data types

- gold Open Access which fosters wider collaboration and increased citations

- maximum visibility for your research: over $100 \mathrm{M}$ website views per year

At $\mathrm{BMC}$, research is always in progress.

Learn more biomedcentral.com/submissions 